\title{
The Implementation of the Lesson Study Approach to Secondary Education in Greece: The Case of the Literature Lesson
}

\author{
Eurydice-Maria Kanellopoulou \\ University of the Aegean \\ Rhodes, Greece \\ Maria Darra \\ University of the Aegean \\ Rhodes, Greece
}

\begin{abstract}
The main purpose of the present study is lesson study's utilization in secondary education in Literature lesson. Specifically, the task is to investigate both the effectiveness of the lesson study approach to improve the quality of the teaching-learning process, as well as conditions and difficulties for its effective implementation in the classroom. In addition, the attitudes, perceptions and suggestions of participating teachers and students for more effective teaching of the research lesson. The qualitative method was selected and recorded transcripts, design, observation, reflection and revision of the research lesson, as well as questionnaires for teachers and pupils were used as data collection tools. The survey was conducted in a general lyceum in eastern Attica from February12 to April 1, 2016. The director and all the four teachers, initially, of the school unit, as well as the two classes of the 2nd Lyceum with 31 students participated. Research data was analyzed through the Atlas.ti program. The study concludes that LS contributes significantly in growing cooperative culture among teachers and in their professional development, as well as in students' learning. In addition, the study demonstrates all necessary conditions for effective implementation of LS, such as detailed planning of research lesson and teachers' supportive participation. In conclusion, the study reports difficulties, which may undermine lesson study's implementation such as members leaving the group, teachers feeling unfamiliar and anxious with their colleagues monitoring their teaching.
\end{abstract}

Keywords: lesson study; collaborative teaching design; research lesson; secondary education; professional development. 


\section{Introduction}

The implementation of innovative teaching approaches constitutes an important factor of the improvement of the education provided. The release of teachers from the isolation of the room and the promotion of their collaboration and professional development within the school, as well as the improvement of pupils' knowledge, are the main features of the lesson study (Rekalidou, 2012). More specifically, from the investigation and study of the relevant literature regarding the importance of the use of LS in the upgrading of the educational work produced, it follows that:

- LS builds interpersonal relationships and motivates teachers to develop and improve their performance, which is reflected in students' performance (Caccavale, 2017; Doig \& Groves, 2011; Hamzeh, 2014; Thompson, 2015).

- Professional development is directly linked to the inter-school cooperation of teachers, which functions as a form of self-education (Nauerth, 2015; Papanaum, 2005).

- LS can be successfully implemented in Greece, as it is the most effective and widespread form of training in other countries. It cultivates collectivity and full assimilation of innovative theoretical and practical teaching applications. Furthermore, the autonomy that teachers may absorb through this procedure, as well as the time and the way they are implemented, make it one of the most appropriate forms of in-school training (Drenogianni \& Primerakis, 2008).

- LS's success is attributed to the networking of teachers' teams that implement it, and to the awareness of results to other LS network groups with the publication of their conclusions (Chokshi \& Fernandez, 2005).

- No matter how many its advantages are, LS also presents some drawbacks in its implementation, such as the lack of time for co-workers and the fear of exposure to team members and their subsequent criticism (Lenski, et al., 2009; Lucas, 2014).

From the above and considering: a. that within the context of the design and application of the lesson study approach to school reality, cooperation and feedback between teachers is enhanced to improve the teaching and learning process and their professional development; and $b$. the lack of relevant research into the Greek educational reality, it is widely understood that the certification of LS's effectiveness in the classroom consists of particular interest. This is the purpose of this research work.

\section{The improvement of teaching literature course in lyceum through lesson study approach: theoretical approach}

Lesson study is an innovative learning process for students and teachers firstly appeared in Japan.

In order for its implementation to be completed, teachers usually spend 10-15 hours in 3-4 weeks (Fernandez, 2002) on the following stages:

1. setting goals.

2. planning the research lesson.

3. teaching, observing and data collecting of the research lesson.

4. evaluating- feedback and re-teaching. 
5. reflection - formulation and sharing final results.

At the stage of setting goals, teachers of the same sector in a school unit, they form a group of 3-6 people and determine the goals that their pupils aspire to achieve. They are looking for an important subject for students that is of interest or learning difficulty. They explore through brainstorming, in the context of a fruitful dialogue, strategies and teaching methods that will direct their students to gain knowledge of the subject.

This lesson will realize the goals of learning and the development of students, and in particular the emphasis is not on what they will learn, but rather on how they will learn (Rekalidou, 2012). In the design of the course, teachers select a unit from the curriculum that is directly related to this subject, and cooperatively plan a research course in detail by anticipating the expected questions and questions from their students (Stepanek, et al., 2007).

The lesson will teach a member of the group, and the rest will observe and collect data on the teaching and acquisition of knowledge of pupils (Shaun, 2014). Based on these data, the team proceeds to evaluate the feedback of the research lesson without criticizing the instructor and, if necessary, re-teach the course to another section by another member of the group (Hiebert, et al., 2002; Rekalidou, 2012).

The presentation of LS shows that it has several advantages, which improve the learning process, but also certain shortcomings that make it difficult to apply generally.

A positive feature of LS is to support the ongoing learning of students and teachers through the evaluation of research teaching. LS contributes to the development and cultivation of students critical thinking, with the contribution of the team-collaborative method, as well as of teachers, who focus more on students' thinking (Coenders \& Verhoef, 2018; Stepanek, et al., 2007).

The latter participate more actively in the learning process through teamwork, developing important skills that improve their school performance (DarlingHammond \& Richardson, 2009).

Teacher learning in the context of LS results from the observation of the teaching of a teacher who does not hesitate to expose his colleagues (Cerbin \& Kopp, 2006). As there is no hierarchical relationship between the participating teachers but mutual relations of cooperation and communication, LS is guided by teachers themselves. Teachers, along with the promotion of their professional knowledge, have a positive impact on the school culture. By cultivating cooperation, collectivity and co-ownership (Lewis \& Hurd, 2011), rather than individualism and competition, a better, more friendly and efficient work environment is created. Also, pupils get better learning outcomes (Berry, et al., 2009).

Another important feature of LS is the existence of the research lesson. In order to carry it out, teachers freely express their views and cooperatively form a common understanding of their teaching (Lewis \& Hurd, 2011). Teachers for the course design analyze students' thinking patterns and co-decide the appropriate teaching methods of teaching. Their ideas are tested in practice, tested and adopted, discarded or modified. This process encourages teachers to improve their teaching style by taking creative initiatives that motivate them to continually improve them. In LS, teachers actively participate as researchers to 
achieve a common goal in a voluntary rather than coercive way (Rekalidou, et al., 2014).

The difficulties faced by teachers when participating in LS are, first of all, related to the time it takes. The limited schedule of the school timetable, the volume of the curriculum and strict adherence to the curriculum stand as an obstacle against its implementation. The involvement of teachers is also hampered by the lack of a culture of cooperation and collegiality. During the LS phases, tensions and conflicts may arise between the participating teachers (Mynott, 2017). The lack of cooperative culture can jeopardize team cohesion and lead to its breakdown, frustrating the LS process (Rock \& Wilson, 2005). In addition, attending the course by other teachers may cause additional stress to the teacher who is accustomed to classroom isolation. Another difficulty may be the superficial application of LS (Chokshi \& Fernandez, 2004).

However, extending its application to more and more subjects and levels of education in different countries suggests the possibility of overcoming these difficulties.

\section{Purpose and research questions}

The main purpose of this paper is to investigate the effectiveness of the lesson study approach in the classroom. In particular, the task is to investigate: a. the effectiveness of the lesson study approach to improve the quality of the teaching-learning process, b. conditions and difficulties for its effective implementation; and c. the attitudes, perceptions and suggestions of participating teachers and students for more effective teaching of the research lesson.

The research questions that the research will attempt to answer are:

1. How does LS enhance student learning?

2. What are the conditions for successful LS implementation in the classroom?

3. What are the difficulties of its implementation?

4. What are the suggestions of participating teachers and pupils for more effective future teaching of the research lesson?

5. How is the LS contribution of participating teachers and pupils evaluated in improving the quality of the educational process?

\section{The method}

The qualitative method was selected for carrying out the survey. As datacollection tools were used transcripts of the teachers who participated in lesson study and teachings (traditional and research lesson). Furthermore, sources included calendars that were completed during the implementation of the lesson study by the facilitator and the group recorder, as well as the protocols for planning, observation, reflection and revision of the research lesson. Moreover, as data were used students work as well as questionnaires were completed by teachers and pupils. The questionnaires also generated quantitative data, which were used to enhance in-depth analysis of the quality data. The existence of the above-mentioned different data sources contributed through triangulation to the validation of research results, which give it credibility and validity (Robson, 2010). 
that they understood the lesson and wanted the new way of teaching to be repeated, while few students kept a neutral stance. Moreover, a large percentage of the students answered that the teaching method kept their interest in the lesson, while the others kept a neutral stance.

2. Conditions for the successful implementation of the LS.

Detailed planning of LS is a prerequisite for its successful implementation and has dominated the meetings of the teachers' team. Also, the teachers in the LS planning questions answered in their entirety that they had been well informed about the process. The enrichment, improvement, integration and faithful observation of the team's protocol design of the research lesson reveals that all its members had realized its importance for the success of the research lesson.

3. Difficulties in implementing the LS.

The most significant difficulty observed was the withdrawal of a member of the group, which did not adversely affect the completion of the LS. The implementation difficulties highlighted by the participating teachers were initially identified in anxiety, stemming from the lack of familiarity of teachers with the follow-up of teaching by other colleagues. However, the group faced this anxiety creatively. They also reported the time pressure and the school's logistical infrastructure. A teacher also noted the teacher's lack of spontaneity as a difficulty.

From the students' answers regarding the difficulties they encountered in teaching, it follows that (see Figure 2): $68.75 \%$ of the students did not notice any difficulty, $12.5 \%$ of the students reported that their anxiety was difficult, the same percentage considered difficulty in understanding the parallel text, and $6.25 \%$ of students find a difficulty in lacking participation because of inherent shame and hesitation.

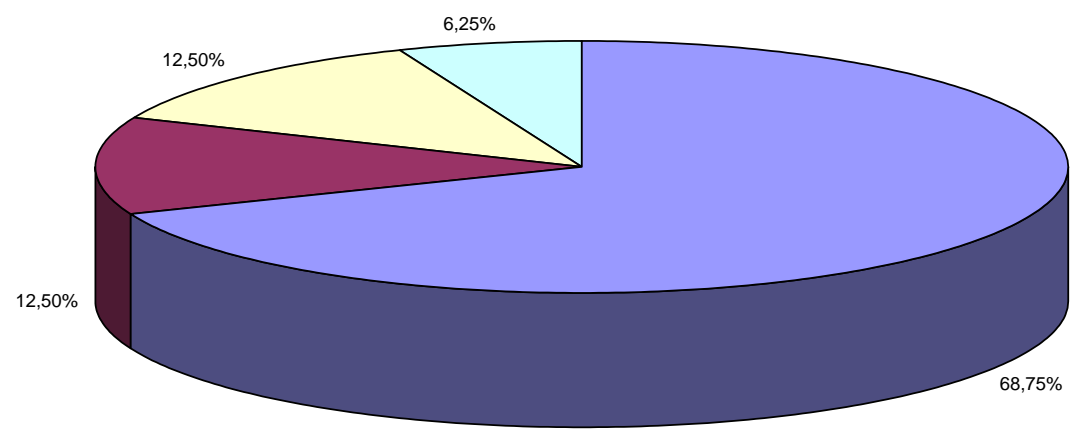

$\square$ No difficulty $\square$ Stress $\square$ Understuding of the parallel text $\square$ Lack of participation due to innate shyness and hesitation

Figure 2: Difficulties encountered by students during teaching.

4. Suggestions of participating teachers and pupils for more effective future teaching of the research lesson. 
The teachers unanimously proposed to give even greater emphasis to students' way of thinking, so that by making use of their previous knowledge, they can become more autonomous, cultivating their critical thinking and ability. They also noted the following suggestions for a better implementation of LS: LS implementation planning from the beginning of the school year, informing teachers about their LS volunteering and appropriate planning and selection of research topics, according to the needs of the students.

From the answers of the students regarding their suggestions for improvement of the research lesson, it is clear that (see Figure 3): $31.25 \%$ answered that their lesson fully satisfied them and did not suggest any improvement, the same percentage suggested improvement of the technological equipment of the school, $25 \%$ of the duration of the lesson so that there is no time pressure on the response of the exercises, $6.25 \%$ the inclusion of Art in the lesson and the $6.25 \%$ lesson once a month.
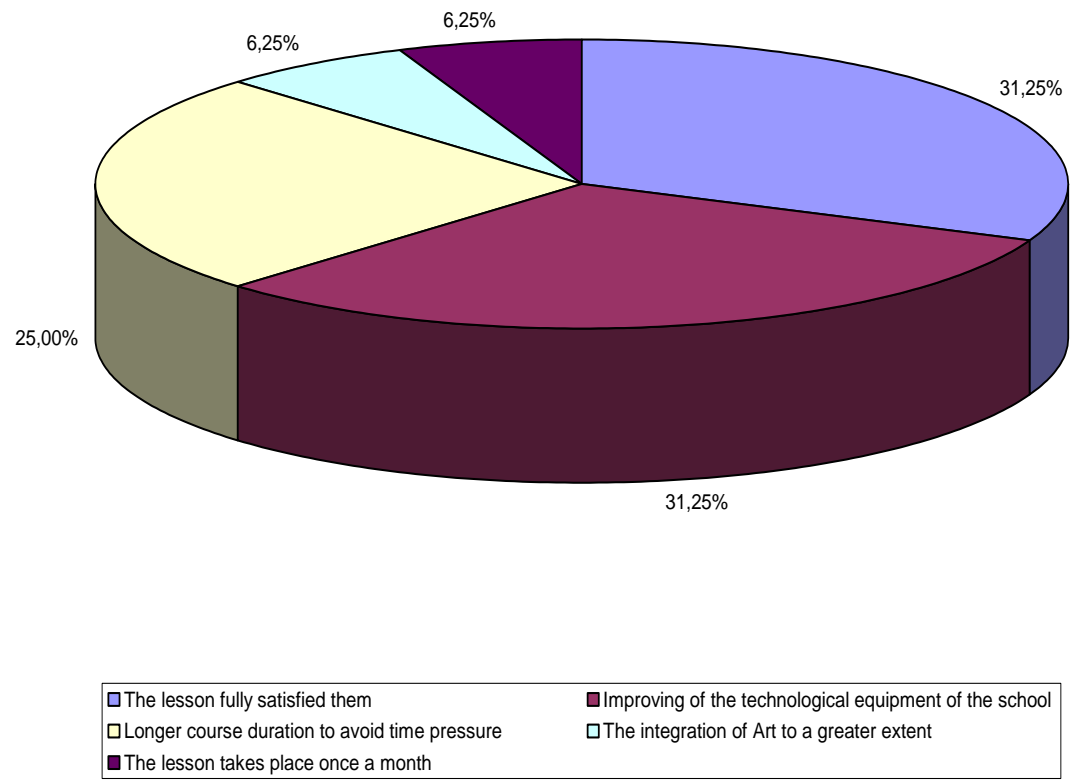

Figure 3: Suggestions for improving a research lesson by students.

5. Evaluation of the contribution of LS by participating teachers and students in the upgrading of the educational process.

Teachers in their entirety positively evaluated the research lesson. The evaluation of LS highlighted its positive impact on teacher collaboration. The application of the collaborative method, the use of New Technologies and the integration of Art in teaching were also positively evaluated. Knowledge of how students learn, as well as predicting the difficulties they may face, have been positively evaluated by the teachers.

The students also evaluated the teaching positively. In particular, they reported on the collaborative method, the audiovisual media and the use of computers.

Finally, students in the open-ended question "What did not you like"? The majority of them did not notice any negative elements. The rest said that the 
research lesson caused them tiredness and anxiety because of the many exercises.

\section{Discussion of research results}

The analysis of the findings of the research revealed that LS significantly enhanced student learning. More specifically, from the oral and written works of the students of the experimental team, a very satisfactory response was recorded to the understanding of the teaching objectives of the research lesson. Their participation in teaching, as depicted in the observation and reflection tools, and especially the weaker students, demonstrates LS's positive contribution to their learning (Coenders \& Verhoef, 2018). Their responses to the worksheets in individual and group work reveal that the enrichment of the teaching of the research course has positively influenced the acquisition of knowledge. Teachers' views expressed at the meeting after the research course agree with this result as they all consider LS to have helped all students to respond successfully to the lesson (Caccavale, 2017). In addition, for LS's contribution to student learning, the answers of the students of the experiment team themselves were particularly important. The pupils stated as a whole that they fully agree to the question of understanding the objectives of the course. The same percentage of students was also observed in the response to the objectives of the course.

These findings highlight the detailed planning and successful implementation of the research lesson, which contributed to the achievement of LS's basic goal, namely student learning (Stepanek, et al., 2007). Also, the majority of students responded that they had a good understanding of the lesson and wanted the new way of teaching to be repeated, while few students replied that they neither agreed nor disagreed. Furthermore, a large percentage of students answered that the new way of teaching kept their interest in the lesson unchanged, while the others did not agree or disagree. These results demonstrate that LS significantly helps pupils to acquire knowledge (Lewis \& Hurd, 2011). However, the small percentage of pupils who do not agree but who do not disagree can be attributed to various causes. First of all, they were invited to participate in a new way of teaching with which they are not particularly familiar. They also had to answer several questions individually and in groups and use New Technologies in one of them. Possibly, time pressure influenced their response.

The above positive effects of LS on students require the successful completion of the research lesson. Its success, as impressed by this research, is directly dependent on the detailed planning of its teaching, as well as the subject of the research lesson, which must respond to learning needs (Stepanek, et al., 2007). The findings of the research have shown that the detailed design of the research lesson addressed the participating teachers in all their meetings. The enrichment, improvement, integration and faithful observation of the project's design protocol by the team reveals that all its members had realized the great importance of planning for the successful outcome of the project. Even at the post-research meeting where useful conclusions were drawn, evaluationfeedback mainly concerned the planning of the course. Teachers, moreover, replied that they fully agree-agree with the questions about the initial planning and the LS cycle. This finding shows that all of the teachers were well informed about the LS process. Also, research has found that the participation of teachers 
in a climate of mutual respect, compassion and collegiality is also important for the success of LS (Lewis \& Hurd, 2011).

On the contrary, various difficulties may undermine the conduct of the LS. In the present study, the most significant difficulty observed was the withdrawal of a member of the group. However, this departure did not negatively affect its completion. Another difficulty that has been recorded is related to the lack of familiarity of teachers with the follow-up of their teaching by other colleagues. The stress resulting from this report was expressed as a difficulty by the teachers who, however, did it creatively in teaching the traditional and research lessons.

Another difficulty identified by this research is related to the logistical infrastructure of the school unit. All participant teachers reported a small technical problem that was created due to the age of computers and was delayed but did not prevent the successful completion of the research lesson.

Another inhibitory factor for LS's success, according to the participants' view, may be the lack of time available in the school curriculum. Also, a teacher's lack of spontaneity was reported as a difficulty. This result can be attributed to the teaching of the research lesson, which presupposes the faithful observance of the course design protocol already agreed, without the teacher to self-act as is customary by some. Of the students, the majority did not mention any difficulty. Stress and parallel text processing also hampered a small percentage of students. A much smaller percentage of students reported difficulty in inherent shame and hesitation. The difficulty of the latter can be attributed to the existence of other teachers in the classroom.

Teachers in their proposals for more effective implementation of LS in future teachings stressed the importance of proper and timely planning and planning of the process with the beginning of the school year. The design of the particular research lesson was realized according to the students' cognitive level and their learning needs. Also, the students' suggestions for the future implementation of LS were of particular interest.

Several students replied that they did not need any improvements, so they did not make any suggestions. The same percentage of students suggested improving the logistics infrastructure and a smaller percentage of the duration of the course. A much smaller percentage suggested the inclusion of Art to a greater extent and the same percentage the research lesson would be held once a month. Teachers, at the reflection stage, after positively evaluating the research lesson, highlighted the problem with computers and agreed that the time they had available to the students in relation to the exercises was marginally sufficient. This result clearly indicates the importance of specific LS phases for future teaching.

The research also highlighted the remarkable contribution of the collaborative method, which was used in LS, to students' learning. Also, the proper use of New Technologies and the incorporation of Art strengthened students in the learning process.

LS's contribution, according to the school principal and the participating teachers, was highly appreciated in the upgrading of the educational process. Its positive assessment by the Director in this research stems from the excellent cooperation of teachers and the students' universal and active participation in 
the research lesson, two conditions which contributed to the improvement of the educational work produced (Thompson, 2015).

\section{Conclusions}

From the analysis of the data and the results of the research, there are remarkable conclusions about the positive effects of LS on teachers and pupils. First of all, LS, according to all the participating teachers, has made a significant contribution to building cooperation between them, to the smooth operation of the school, to working together and to the fruitful exchange of views, ideas, arguments and teaching techniques. LS widened their knowledge and promoted their professional development, which was directed by themselves, with their voluntary participation and worked as a form of training within the school unit. However, an issue that arose was the withdrawal of a member of the team, which could endanger even frustrating the implementation of the LS. Consequently, the lack of incentives is a significant inhibiting factor for the voluntary participation of teachers in LS.

The positive effects of LS were also recorded and evaluated by students. The understanding of the research lesson by the majority of students and their positive response to its future application is another conclusion of the research. For the success of LS, the prerequisites are its detailed design, which should be based on student needs as well as honest and meaningful cooperation between teachers.

Disagreements or personal confrontations may undermine the group's consistency. Also, the stress of the exposure of teachers, who were invited to teach in front of the other members of the team, is a difficulty, which in this case has been successfully dealt with. Also, the upgrading of the logistics infrastructure and the lack of available time on the timetable are issues that can be addressed in an appropriate way by the school administration.

However, a significant limitation of the research is that it was conducted in a school with a relatively small sample of teachers and pupils and for this reason its results can not be generalized. In addition, the implementation of the lesson study due to time constraints of the research was applied only to a teaching subject, Literature and only to the two classes of the $2^{\text {nd }}$ lyceum. Applying it to more teaching subjects and more students would enhance the credibility of the research. Besides, the choice of the research method, based on the qualitative analysis, does not aim at generalizing the findings.

In conclusion, the positive results of LS in the particular school unit indicate that this innovative teaching method could be the subject of further research. The implementation of the LS in more secondary schools, high schools and lyceums and in different teaching subjects is a proposal for further research. The conditions for creating and expanding a network of communication between the different school units involved in the LS and the creation of a LS quality assurance system to avoid its superficial application in the Greek education system could also constitute proposals for further study. 


\section{References}

Berry, B., Daughtrey, A., \& Wieder, A. (2009). Collaboration: Closing the effective teaching gap. Center for Teaching Quality (CTQ).

Caccavale, L. (2017). Investigating professional development models that assist teachers in developing high quality teaching skills: An action research study. (Doctoral Dissertation). College of William and Mary, VA, USA. Retrieved from https://publish.wm.edu/cgi/viewcontent.cgi?referer=https://www.google.gr/ \&httpsredir $=1 \&$ article $=1152 \&$ context $=$ etd

Cerbin, B., \& Kopp, B. (2006). Lesson study as a model for building pedagogical knowledge and improving teaching. International Journal of Teaching and Learning in Higher Education, 18 (3), 250-257.

Chokshi, S., \& Fernandez, C. (2004). Challenges to importing japanese lessons study concerns, misconceptions, and nuances. Phi Delta Kappan, 85 (7), 520-525. doi/10.1177/003172170408500710

Chokshi, S., \& Fernandez, C. (2005). Reaping the systemic benefits of lesson study: Insights from the U.S. Phi Delta Kappan, 86 (9), 674-680. doi/10.1177/003172170508600911

Coenders, F., \& Verhoef, N. ( 2018). Lesson study: professional development (PD) for beginning and experienced teachers. Professional Development in Education. Doi: 10.1080/19415257.2018.1430050

Creswell, J. (2011). Research in education. Design, Conduct and Evaluation of Quantitative and Qualitative Research. N. Kouvarakou Trns. Edited by: C Tsorbatzoudis. Athens: Ion.

Darling-Hammond, L., \& Richardson, N. (2009). Teacher learning: What matters? Educational Leadership, 66 (5), 46-53.

Doig, B., \& Groves, S. (2011). Japanese lesson study: Teacher professional development through communities of inquiry. Mathematics Teacher Education and Development, 13 (1), 77-93.

Drenogianni, E., \& Primerakis, G. (2008). Digital teaching scenarios for primary school: Exploring their content with an emphasis on structural, morphological and methodological design elements. Science and Technology Issues in Education, 1 (2) ,143-175. Available at:

https://earthlab.uoi.gr/thete/index.php/thete/article/view/7

Fernandez, C. (2002). Learning from japanese approaches to professional development: the case of lesson study. Journal of Teachers Education, 53 (5), 393-405. doi/10.1177/002248702237394

Hamzeh, F. (2014). Lesson study-Building communities of learning among pre-service scence teachers. (Doctoral Dissertation). University of Windsor, Canada. Retrieved from https://scholar.uwindsor.ca/cgi/viewcontent.cgi?referer=https://www.google gr $/ \&$ httpsredir $=1 \&$ article $=6113 \&$ context $=$ etd

Hiebert, J., Gallimore, R., \& Stigler, J. (2002). A Knowledge base for the teaching profession: What would it look like and how can we get one? Educational Researcher, 31 (5), 3-15. / doi/10.3102/0013189X031005003

Lenski, S., Caskey, M., \& Anfara, V. (2009). Using the lesson study approach to plan for student learning. Middle School Journal, 40 (3), 50-57. doi/abs/10.1080/00940771.2009.11495587

Lewis, C., \& Hurd, J. (2011). Lesson study step by step. How teacher learning communities improve instruction. Portsmouth, NH, USA.

Lucas, M. (2014). Lesson study, a means for fostering collaborative reflection: effects on the selfefficacy and teaching practices of developmental education college success course instructors. (Doctoral Dissertation). Arizona State University, AZ, USA. Retrieved from 
https://repository.asu.edu/attachments/134840/content/Lucas_asu_0010E_13 671.pdf

Mynott, J. P. (2017). A Primary Head Teacher's Exploration of Lesson Study. (Doctoral Dissertation). University of Hertfordshire, UK. Retrieved from https://uhra.herts.ac.uk/bitstream/handle/2299/18330/14107916\%20Mynott\% 20John $\% 20$ Final $\% 20$ Submission.pdf? sequence $=1$

Nauerth, D. (2015). The impact of lesson study professional development on teacher self-efficacy and outcome espectancy. (Doctoral Dissertation). Kansas State University, KS, USA. Retrieved from https://krex.kstate.edu/dspace/bitstream/handle/2097/19048/DeborahNauerth2015.pdf;seq uence $=1$

Papanaum, Z. (2005). The role of educating teachers in their professional development: why, when, how. Education and professional development of the teacher. Edited by: G. Bagakis, 82-91. Athens: Metechmio.

Rekalidou, G. (2012). Improving teaching. The case of lesson study. Pedagogy- Theory and Practice, 5, 98-109.

Rekalidou, G., Karadimitriou, K., \& Moumoulidou, M. (2014). Applying lesson study to students. Collaboration, reflection and feedback. Research in Education. DTH. Available at: http://www.ereunastinekpaideusi.gr

Robson, C. (2010). Real-world research. Translated by V. Dalakou, \& K. Vassilikou. Edited by: K. Michalopoulou, \& F. Kalyva. Athens: Gutenberg.

Rock, C., \& Wilson, C. (2005). Improving teaching through lesson study. Teacher Education Quarterly, 32 (1), 77-92.

Shaun, A. (2014). Perfect CPU Teacher-Led. U.K., Independent Thinking Press.

Stepanek, J., Appel, G., Leong, M., Turner Mangan, M., \& Mitchell, M. (2007). Leading lesson study. A practical guide for teachers and facilitators. CA, USA.

Thompson, D. (2015). An analysis of the perceived impact of lesson study on improving secondary school STEM teacher effectiveness. (Doctoral Dissertation). University of Central Florida, FL, USA. Retrieved from http://stars.library.ucf.edu/cgi/viewcontent.cgi?article=2310\&context=etd 